\title{
Income Inequality: How Do Racial and Gender Differences Influence the Incomes in US
}

\author{
Ting Liu, Enhao Yang, Zhiliang Wang* \\ School of Management, Shanghai University, Shanghai, China \\ Email: ^zlwang@shu.edu.cn, lenaliu@shu.edu.cn, eyang2@albany.edu
}

How to cite this paper: Liu, T., Yang, E.H. and Wang, Z.L. (2019) Income Inequality: How Do Racial and Gender Differences Influence the Incomes in US. Journal of Human Resource and Sustainability Studies, 7, 233-243.

https://doi.org/10.4236/jhrss.2019.72014

Received: March 28, 2019

Accepted: June 1, 2019

Published: June 4, 2019

Copyright $\odot 2019$ by author(s) and Scientific Research Publishing Inc. This work is licensed under the Creative Commons Attribution International License (CC BY 4.0).

http://creativecommons.org/licenses/by/4.0/

\begin{abstract}
Income inequality is a serious social economic issue in many countries. The issue is deteriorated due to the complex social environment and demographic composition in the Unites States. This study focuses on the racial and gender factors which influence workers' income. And the easy-qualified year of schooling and working-year are chosen as the other two factors. Basing on the Ordinary Least Square (OLS) analysis, the selected factors are qualified to understand their influence degree in income inequality. By comparing the coefficients of the factors, we find the inner relationships between the factors and income inequality. The precise results not only provide a chance for people to examine their income levels, but also help the government to develop fair policies.
\end{abstract}

\section{Keywords}

Income Inequality, OLS Regression, Racial, Gender

\section{Introduction}

Income inequality has been a seriously social issue for many years in the United States (US). US is composed of different races come from different countries, such as European, African, Asian [1]. Generally, white people get higher incomes than other racial people in average [2]. Some economists believe that it is the racial discrimination causes the gap expansion between poverty and rich. Owing to racial differences, sometimes even people do the same job and may get unequal payments [3]. However, the incomes are influenced by many factors like gender, years of schooling, working-years, etc. Even a small difference in some special factors will cause large change in workers' incomes. Therefore, it is critical to separately quantify the impact of different influencing factors on income, especially the racial and gender factors. 
In this study, the data of about 95,796 people's income situations and their individual situations for the factors ae corllected and used to show the impact of different factors on workers' income and to identify some factors that lead to the inequality. The OLS regression is performed on the factors of wage, race, gender, years of schooling, working-age and squared working-age. By analyzing the result from Stata, the influence levels of different factors on personal income have been well quantified. Based on the quantitative results, the government can formulate strategies in a targeted manner, and the public can find more effective ways to raise their wages.

\subsection{The Statement of the Problem}

The characteristics of liberalism in economic operations are obvious in the liberal traditional US. The degree of government intervention in the development of the market economy is relatively low. After the war, several Republican governments in the United States were more inclined to intervene in low-level economic activities, especially the Reagan administration. Reagan advocates it is more necessary to be dependent on the state, especially the individual's initiative. He does not advocate that the federal government should take positive action to expend the scale. He believes that most economic decisions should be made according to market rules, not based on bureaucratic plans. In this way, the US government's intervention in economic activities is limited to not deteriorating the liberalization of economic activities. It regulates economic activities only through the formulation of laws and regulations, monetary policies, and the use of fiscal policies, rather than adopting planning adjustments and administrative interventions [4]. Caused by historical factors, income inequality in the United States is different from other countries.

Recent studies demonstrated that income inequality is related to mortality rates [5]. Due to the historical factors, the problem of income inequality is serious in the United States. Piketty made researches on income and wages from 1913 to 1998 in the United States and found in that period, the rentiers have been replaced by the working rich [6]. So, in different period, the problem of income inequality changes. Ross and Dorling explore the relationship between the age and the income inequality in five countries [7]. Hirsch analysis the effect of age from cross-sectional analysis and gets the conclusion that age is one of the factors which affects wage. The elder the people are, the higher the wage is [8]. It is essential to prove whether these results fit the real situation in the United States. Leslie discovered three sources which affect wage inequality: gender, racial, ethnic and examined the wages of Asians, blacks, and Latinos, relative to whites and separately for women and men [9]. This result can be used to most countries, but the history and development of the United States is a bit different from other countries. The construction of a harmonious society is based on the stable development of the economy, and the stable development of the economy requires us to pay attention to fair competition and income inequality. So, it is necessary to get the conclusion of the income inequality in the United States. 


\subsection{Research Question}

To what extent does race and gender affect workers' income? Which is the main factor?

\subsection{Hypotheses}

Based on the research question, the following three pairs of hypotheses are formulated to guide this study:

$\mathrm{H}_{0}$ : There is no significant relationship between the race and the income.

$\mathrm{H}_{1}$ : There is significant relationship between the race and the income.

$\mathrm{H}_{2}$ : There is no significant relationship between the gender and the income.

$\mathrm{H}_{3}$ : There is significant relationship between the gender and the income.

$\mathrm{H}_{4}$ : The factor of race has a more powerful influence than gender on the income.

$\mathrm{H}_{5}$ : The factor of gender has a more powerful influence than race on the income.

\section{Empirical Studies}

\subsection{Income Inequality}

Income inequality is a global issue. According to Due to recent studies, many scholars focus on income inequality in Europe, in Africa, in Asia, etc. In Europe, studies mainly discuss the income inequality in the Portugal, France and central and eastern of Europe. Teixeira analysis the relationship between FDI and income equality in Portugal and find a time series of that FDI won't cause income equality and human capital mitigate the income equality [10]. Michal and Brzezinski study the changes in income inequality during the Great Recession (2008-2012) in Central and Eastern Europe. They find that changes in the incidence of temporary jobs do not affect income inequality [11]. Garbinti proves that the income inequality decreases from 1970 to 2014 in France. Eventually, in recent years gender plays a less important role in income inequality [12]. Many studies in Africa deliberate that the racial have impact on income inequality. Besides, people who are less educated tend to be especially vulnerable [13]. The income inequality is most serious in South Africa and that erode the gains from economic growth [14]. In Asia, studies consider the diverse background of Asia. In India, spatial factors, rural and urban impact the income inequality [15]. The resource (oil) takes an important role in income inequality in Iran and in low oil revenues regime, income inequality will be decreased by a rise of oil revenues. However, in high oil revenues regime, income inequality would be increased by an increase in oil revenues [16]. According to Chambers and Mclaughlin, the phenomena of income inequality are more serious if the entry regulations of the country are stringent [17]. Above all, income inequality differs from different countries. It maybe caused by several factors like human capital, gender, education, entry regulation, etc. 


\subsection{Income Inequality in US}

Due to the recent news, the income inequality hits a disturbing new threshold. According to Eidelson Josh's report (2018), the slow income growth in US is still uneven [18]. The African-Americans and women seem to suffer particularly unequal treatment, taking relatively lower incomes than others. Figure 1 clearly shows that the education level has strong positive influence on people's average hourly wage. More importantly, under the same education level, men always have a relatively higher wage than women. It proves the gender is an important factor that caused income inequality. It is obviously that if women want to gain same or better treatment on wage, they usually need to have higher education level than men. Implausibly, the women who have the some collage degree education level get less hourly wage than those men only have a high school degree education level in average. It is well known that as the education level increases, more money is needed to pay for tuition. In some cases, high education levels bring high debts instead of high wages to women. Basing on the report, we can suppose that the gender has an impact on personal income. And a more accurate analysis is needed to qualify this relationship.

Figure 2 shows racial inequality problem at education level. Three different races are chosen as examples and noted as White, Hispanic and Black. The education levels use the same measurement as Figure 1. For people in same education level, white people always get highest average hourly wage. The differences are much obvious in high level of education. When people reach college degree, whites can get $27 \%$ more wages than blacks. Generally, people can gain considerable basic wages when they have a college degree or advanced degree, cause that their jobs are professional and require superb skills. When the basic wage becomes as high as 35 dollar per hour, the difference of $10 \%$ income leads to a $\$ 560$ money loss per month. This is unfair that people cannot make up for the loss due to racial problem even by moderately extending working hours.

After finding the inequality problem in education level, the impact of the working-age on people's wages cannot be ignored. From the below graph, the hourly wage of 95 th has grown about $20 \%$ in 17 years. However, the hourly wage of 30th only increases about $5 \%$. Thus, the working-age factor should also be considered.

\section{Methodology}

There are many variables in the data sample such as survey year, person age, sex, race, education year, etc. All of them may have influence for people's income in the sample. After filtering and picking, several main factors are selected, which are wage, race, gender, year of schooling, working-age and squared working-age. Furthermore, the study focuses on black and white people in racial factor because they are the most two sample groups in dataset.

Due to the certain number of factors in the proposition, multiple regression analysis is required and model coefficients are estimated using OLS analysis. The 


\section{Gender Inequality at Every Education Level}

Average hourly wage by gender and degree, in dollars

Men Women

Less than high school degree

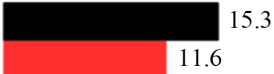

High school degree

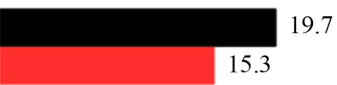

Some college

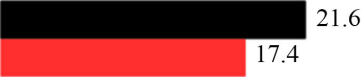

College degree

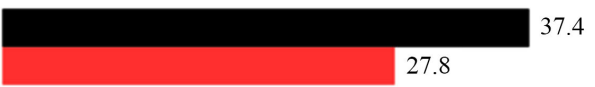

Advanced degree

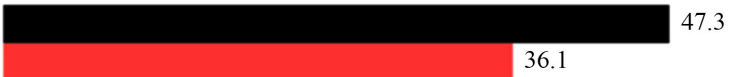

Figure 1. Gender inequality at every education level.

\section{Racial Inequality at Every Education Level}

Average hourly pay by race and degree, in dollars

White Hispanic $\square$ Black

Less than high school degree

High school degree

Some college

College degree

Advanced degree

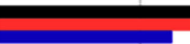

(1)
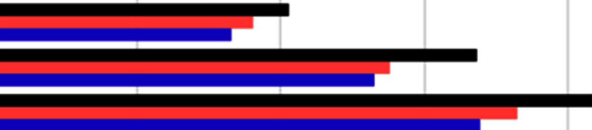

30

50

Education Level

Figure 2. Racial inequality at every education level.

model is built as $\log Y=\beta_{0}+\beta_{1} V_{1}+\beta_{2} V_{2}+\cdots+\beta_{i} V_{i}$. Here, $Y$ is the wage, $\beta_{0}$ is the regression constant. The above five variables are chosen as main objects, so the range for $i$ is from 1 to 5 . Every $\beta_{i}$ here means the coefficient of the corresponding variables to qualify the influence level. Here using log model to estimate the change for wage because it is more clearly on the order of magnitude. In log model, every additional change in variables will cause $\beta_{i} \times 100 \%$ change in wage.

The data used in the paper is collected from Current Population Surveys of IPUMS database and analyzed by the stata.

\section{Results}

\subsection{Relationship between the Influences of Year of Schooling and Working-Age for $\mathrm{H}_{0}, \mathrm{H}_{1}$}

Firstly, the OLS regression analysis of both white and black people in the dataset is made to gain the coefficient for the variables (Table 1). The factor of gender is excluded in this OLS regression. From Table 1, the coefficient for year of schooling is 0.079 , which means that people gain one more school year, their wage will increase about $7.9 \%$, when assuming other conditions are constant. The coefficient lies in the $95 \%$ coefficient interval, means that it is reliable. For 
the working-age, the coefficient is 0.199 which means that the worker can gain $19.9 \%$ more in wage than current income due to one years older. For the working-age squared, the coefficient is -0.002 which means that if a worker gains extra working-age squared, he will lose about $0.2 \%$ in wage. Here the working-age squared has not practical meaning, but it exists to fix the error in this model. Because the working-age does not always have a positive relation with workers' wage. When people retire and become older, their wages will stop increase. If not setting working-age squared which has a negative relation with wage, the model will have a large defect.

After dealing with the data of the three coefficients, especially for the two efficient of year of schooling and working-age, they become comparable. It comes out the temporary conclusion that working-age plays a much important role than year of schooling in the influence on people's wage, due to its largest coefficient.

Before repeating the same steps of regression to gain the information about white people in the samples, guessing-results are proposed that both the factors of year of schooling and working-age have a weak influence for white people. Because many white people families can afford education fee. Besides, white people seem to get more promotion opportunities in limited working years.

Then the same steps of regression are implemented only for white people, and the results are shown in Table 2. From Table 2, the coefficients of white people change from 0.079 to 0.077 for year of schooling and from 0.199 to 0.202 for working-age. Here, every coefficient is checked and ensured in the $95 \%$ confidence interval. So, the results are reliable, and we can use the results to analysis. The result for year of schooling fits the guess, but the guess on age influence is wrong. Compared with other people in the sample, white people have a relatively lower coefficient for year of schooling but a relatively higher coefficient for working-age, means that white people have a relatively advantage on working-age factor compared with other samples. The working-age is more important than year of schooling for white workers.

The regression for black people is also calculated. The results are shown in Table 3 by repeating the same progress of Table 2 but change the race code to Black. It shows that the coefficient for year of schooling increases from 0.079 to 0.0874 , while the coefficient for working-age decreases from 0.199 to 0.168 . After using t-test to check the reliability of coefficient, we find that all the coefficients here are in the $95 \%$ confidence interval, signifying high reliability. Comparing the two groups of data, we find that the changes for black workers are totally opposite to white workers. Specifically, the benefit from longer school year for black people is higher than that for white people; but the working-age factor for black people has weak influence than that for white people.

Then the change between black workers' and white workers' coefficient on year of schooling and working-age are determined. For the year of schooling factor, the difference is about 0.0109 (higher in white workers) which means that 
the change in wage from extra one school year is $1.09 \%$. Such small difference in wage means that the year of schooling factor plays the similar role in different races. The result further indicates that the year of schooling factor is not a main reason for the increased gap between the rich and the poor shown in Figure 3. The same compartment is performed for the working-age factor. The coefficient of white workers is about 0.341 higher than black workers. Laterally speaking, the working-age factor plays an important role in increasing wages of white and black workers. And horizontally speaking, white people do get more benefits from the above factors.

\section{The Rich Get Richer}

Cumulative percentage increase in hourly real wages, by wage percentile

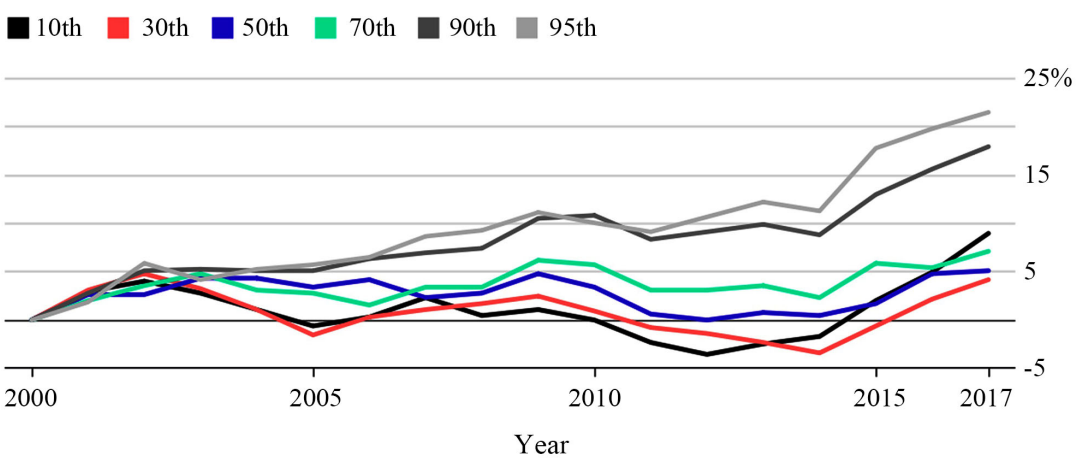

Figure 3. The rich get richer.

Table 1. OLS analysis results of white \& black people.

\begin{tabular}{cccc}
\hline \multicolumn{3}{c}{ OLS analysis results } \\
\hline Variables & Coefficient $(\beta)$ & Error & {$[95 \%$ conf. interval] } \\
Year of schooling & 0.079 & 0.0009856 & $0.0774 / 0.0813$ \\
Working-age & 0.199 & 0.0015626 & $0.1959 / 0.2021$ \\
Squared working-age & -0.002 & 0.0000196 & $-0.00218 /-0.00211$ \\
\hline
\end{tabular}

Table 2. OLS analysis results of white people.

\begin{tabular}{cccc}
\hline \multicolumn{4}{c}{ OLS analysis results } \\
\hline Variables & Coefficient $(\beta)$ & Error & {$[95 \%$ conf. interval] } \\
Year of schooling & 0.077 & 0.0010879 & $0.0744 / 0.0786$ \\
Working-age & 0.202 & 0.0017269 & $0.1989 / 0.2057$ \\
Squared working-age & -0.002 & 0.0000216 & $-0.00222 /-0.00213$ \\
\hline
\end{tabular}

Table 3. OLs analysis results of blackpeople.

\begin{tabular}{cccc}
\hline \multicolumn{3}{c}{ OLS analysis results } \\
\hline Variables & Coefficient $(\beta)$ & Error & [95\% conf. interval] \\
Year of schooling & 0.087 & 0.0034419 & $0.0807 / 0.0942$ \\
Working-age & 0.168 & 0.0048155 & $0.1588 / 0.1777$ \\
Squared working-age & -0.002 & 0.0000597 & $-0.00193 /-0.00170$ \\
\hline
\end{tabular}




\subsection{Relationship between the Influences of Year of Schooling and Working-Age for $\mathrm{H}_{2}, \mathrm{H}_{3}$}

After quantified the racial influences, the same method is used to check the gender inequality. Wage, year of schooling and working-age are chosen as three main variable factors and the regression is based on gender.

The analysis of male is shown in Table 4 . The coefficient of year of schooling is 0.085 and the coefficient of working-age is 0.033 . The meaning of these two coefficients is as same as the above analysis in racial inequality. The coefficient of year of schooling is more than twice of working-age, implying the education background is much more important in male's career.

The coefficient of year of schooling is 0.105 and the coefficient of working-age is 0.027 for females. It means the wage will increase $10.51 \%$ and $2.67 \%$ when female workers increase their school years for one more year and becomes one year older. Besides, the coefficients are reliable because the coefficients are all in the $95 \%$ confidence interval.

Comparing the above results, we notice that the coefficient of year of schooling for female is relatively high, which means that the year of schooling can bring female more benefits compared with male. Unfortunately, this small difference exhibits very limited contribution to female's salary growth. Meantime, the coefficient of working-age for female is lower than male, which means that male can gain more benefit from being older compared with female.

Although the specific values are different, the relationship of these factors is consistent with the results in males. Such relationship between year of schooling and working-age in the gender analysis is the opposite of the above racial analysis, that year of schooling plays a pivotal role when gender difference is considered (Table 5).

\subsection{Relationship between the Influences of Year of Schooling and Working-Age for $\mathrm{H}_{4}, \mathrm{H}_{5}$}

Combining the data and analysis of the above parts, we can draw Table 6 to conclude whether the factors of race and gender have powerful influences on the income. First of all, we can know that race plays an important role based on working-age factor-as the length of working year becomes longer, the increase in white wages is much higher than that of blacks. This huge advantage is 31 times greater than the advantage that white people have gained in education. Secondly, gender plays a powerful role based on year of schooling factor. It is also noteworthy that women will get higher wage increase when they are working for long years.

Table 4. OLS analysis results of male.

\begin{tabular}{cccc}
\hline \multicolumn{3}{c}{ OLS analysis results } \\
\hline Variables & Coefficient $(\beta)$ & Error & {$[95 \%$ conf. interval $]$} \\
Year of schooling & 0.085 & 0.0013304 & $0.0822 / 0.0874$ \\
Working-age & 0.033 & 0.0003505 & $0.0322 / 0.0336$ \\
\hline
\end{tabular}


Table 5. OLS analysis results of female.

\begin{tabular}{cccc}
\hline \multicolumn{3}{c}{ OLS analysis results } \\
\hline Variables & Coefficient $(\beta)$ & Error & {$[95 \%$ conf. interval] } \\
Year of schooling & 0.105 & 0.0015510 & $0.1021 / 0.1081$ \\
Working-age & 0.027 & 0.0003617 & $0.0260 / 0.0274$ \\
\hline
\end{tabular}

Table 6. Summary of the OLS analysis results.

\begin{tabular}{ccc}
\hline & \multicolumn{2}{c}{ Summary } \\
\hline Variables & Year of schooling & Working-age \\
Difference of Race & $1.09 \%$ (White higher) & $34.1 \%$ (White higher) \\
Difference of Gender & $10.5 \%$ (Male higher) & $2.67 \%$ (Feale higher) \\
\hline
\end{tabular}

\section{Discussion}

After collecting the results of racial inequality and gender inequality in the dataset, the calculated data is compared with the conclusions of Josh (2018). The dataset is collected in a 2010 survey. By comparing the changes, we can not only check whether Josh's statement is reliable, but also qualify how important the various influencing factors are.

Firstly, from the above results, it can be concluded that black people receive more benefits from education than white people. In fact, this is inconsistent with Josh's conclusion that the average white salary of a college degree is the same as that of black people with an advanced degree. According to research, black people with advanced degrees can get much higher hourly wages than white people. A reasonable explanation is that racial discrimination plays an important role. The population cannot be shown in the OLS regression because it only knows the coefficient of the years in school, which means that only the return of the investment in the school year can be known. The big difference between the conclusions of this study and Josh's conclusions is that the racial discrimination shows great impact.

Secondly, we combine the results of the OLS regression with Josh's conclusions in gender factors. According to the regression results, female workers benefit more from investment in education than male workers. Women's return on investment in education is $2 \%$ higher than men. But as Josh said in his report, women have encountered difficult environments compared to men of every educational level. This means that although female workers have high return on investment in education, their average base wages are lower than male.

Thirdly, two kind of people who the potential to earn high wages are selected: Highly educated men and senior whites. And by comparing the data, different people can use different strategies to get higher wages and avoid doing useless things.

\section{Conclusion}

Based on the difference \& commonality of our OLS regression results and Josh's 
conclusions, we conclude that the racial and gender differences actually play important parts in people's income inequality problem in US. On the whole, women and black people are in a weak position in this unequal treatment, and there are few effective ways to regain the disadvantage. Highly educated white males are in an absolute position in rising wages. If the gap between the rich and the poor continues to be larger, the whole economy will be more inefficient. Our current research provides some reference value for government legislation.

\section{Conflicts of Interest}

The authors declare no conflicts of interest regarding the publication of this paper.

\section{References}

[1] Kawachi, I., Kennedy, B.P., Lochner, K. and Prothrow-Stith, D. (1997) Social Capital, Income Inequality, and Mortality. American Journal of Public Health, 87, 1491-1498. https://doi.org/10.2105/AJPH.87.9.1491

[2] Pappas, G., Queen, S., Hadden, W. and Fisher, G. (1993) The Increasing Disparity in Mortality between Socioeconomic Groups in the United States, 1960 and 1986. New England Journal of Medicine, 329, 103-109. https://doi.org/10.1056/NEJM199307083290207

[3] Smeeding, G.T.M. (1997) Cross-National Comparisons of Earnings and Income Inequality. Journal of Economic Literature, 35, 633-687.

[4] Galetti, J. (1985) A Brief History of the United States. 4th Edition, Harper and Luo Press, New York.

[5] Wilkinson, R.G. and Pickett, K.E. (2008) Income Inequality and Socioeconomic Gradients in Mortality. American Journal of Public Health, 98, 699.

https://doi.org/10.2105/AJPH.2007.109637

[6] Piketty, T. and Saez, E. (2003) Income Inequality in the United States, 1913-1998. Quarterly Journal of Economics, 118, 1-39.

https://doi.org/10.1162/00335530360535135

[7] Ross, N.A., Dorling, D., Dunn, J.R., Henriksson, G., Glover, J., Lynch, J. and Weitift, G.R. (2005) Metropolitan Income Inequality and Working-Age Mortality: A Cross-Sectional Analysis Using Comparable Data from Five Countries. Journal of Urban Health Bulletin of the New York Academy of Medicine, 82, 101-110. https://doi.org/10.1093/jurban/jti012

[8] Hirsch, B.T., Seaks, T.G. and Formby, J.P. (1980) Inter-Age and Intra-Age Income Inequality: A Cross-Sectional Analysis. Southern Economic Journal, 46, 1187. https://doi.org/10.2307/1057253

[9] McCall, L. (2001) Sources of Racial Wage Inequality in Metropolitan Labor Markets: Racial, Ethnic, and Gender Differences. American Sociological Review, 66, 520-541. https://doi.org/10.2307/3088921

[10] Teixeira, A.A.C. and Loureiro, A.S. (2019) FDI, Income Inequality and Poverty: A Time Series Analysis of Portugal, 1973-2016. Portuguese Economic Journal, 1-47. https://doi.org/10.1007/s10258-018-00152-x

[11] Brzezinski, M. (2018) Income Inequality and the Great Recession in Central and Eastern Europe. Economic Systems, 42, 219-247.

https://doi.org/10.1016/j.ecosys.2017.07.003 
[12] Garbinti, B., Goupillelebret, J. and Piketty, T. (2018) Income Inequality in France, 1900-2014: Evidence from Distributional National Accounts. Journal of Public Economics, 162, 63-77. https://doi.org/10.1016/j.jpubeco.2018.01.012

[13] Leibbrandt, M., Finn, A. and Woolard, I. (2012) Describing and Decomposing Post-Apartheid Income Inequality in South Africa. Development Southern Africa, 29, 19-34. https://doi.org/10.1080/0376835X.2012.645639

[14] Bhorat, H., Westhuizen, C.V.D. and Jacobs, T. (2009) Income and Non-Income Inequality in Post-Apartheid South Africa: What Are the Drivers and Possible Policy Interventions? https://doi.org/10.2139/ssrn.1474271

[15] Azam, M. and Bhatt, V. (2018) Spatial Income Inequality in India, 1993-2011: A Decomposition Analysis. Social Indicators Research: An International and Interdisciplinary Journal for Quality-of-Life Measurement, 138, 505-522. https://doi.org/10.1007/s11205-017-1683-4

[16] Nademi, Y. (2017) The Resource Curse and Income Inequality in Iran. Quality \& Quantity, 52, 1159-1172. https://doi.org/10.1007/s11135-017-0510-y

[17] Chambers, D., Mclaughlin, P.A. and Stanley, L. (2018) Barriers to Prosperity: The Harmful Impact of Entry Regulations on Income Inequality. Public Choice, 180, 165-190. https://doi.org/10.1007/s11127-018-0498-4

[18] Eidelson, J. (2018) US Income Inequality Hits a Disturbing New Threshold. https://readersupportednews.org/news-section2/318-66/48767-us-income-inequalit y-hits-a-disturbing-new-threshold 